\title{
Modulatory Effect of Environmental Context and Drug History on Heroin-Induced Psychomotor Activity and Fos Protein Expression in the Rat Brain
}

\author{
Giovanna Paolone', David Conversi' ${ }^{2,3}$, Daniele Caprioli', Paola Del Bianco', Paolo Nencini' ${ }^{1,3}$, \\ Simona Cabib ${ }^{2,3,4}$ and Aldo Badiani*, ${ }^{, 1,3}$ \\ 'Department of Human Physiology and Pharmacology, University of Rome Sapienza, Rome, Italy; ${ }^{2}$ Department of Psychology, University of Rome \\ Sapienza, Rome, Italy; ${ }^{3}$ Center for Research in Neurobiology, University of Rome Sapienza, Rome, Italy; ${ }^{4}$ RCCS Fondazione Santa Lucia, \\ Centro Europeo di Ricerca sul Cervello (CERC), Rome, Italy
}

\begin{abstract}
The goal of the present study was to investigate the role of environmental context and drug history in modulating the effects of heroin on locomotor activity and Fos protein expression in the neocortex and striatal complex of the rat. It was found that (I) repeated i.p. administrations of a relatively low dose of heroin $(\mathrm{I} \mathrm{mg} / \mathrm{kg}$, i.p.) induced psychomotor sensitization only when the treatment was administered in a relatively 'novel' environment (ie, a unique test environment distinct from the home cage) but not when the same treatment was administered in the home cage; (2) environmental novelty facilitated heroin-induced Fos expression in the caudate, particularly in its most caudal regions; (3) environmental context also modulated heroin-induced Fos expression in the nucleus accumbens and in the neocortex; (4) repeated exposures to heroin dramatically altered its effects on Fos expression in the caudate and in the neocortex; and (5) Fos protein levels in the postero-dorsal caudate, in the shell of the nucleus accumbens, and in the barrel field cortex predicted most of the variance in heroin-induced activity scores, as shown by multiple regression analysis. The present report demonstrates that environment and drug history powerfully interact in shaping the neurobehavioral response to heroin, as previously shown for amphetamine and cocaine. Thus, a full understanding of the mechanisms responsible for the neurobehavioral adaptations produced by addictive drugs will also require taking into due consideration the environment in which drugs are experienced.
\end{abstract} Neuropsychopharmacology (2007) 32, 26 I -2623; doi:I0.1038/sj.npp. I30 I 388; published online 28 March 2007

Keywords: environment; Fos; heroin; sensitization

\section{INTRODUCTION}

Intermittent treatment with addictive drugs is known to produce long-lasting neurobehavioral adaptations in laboratory rodents. It is reasonable to assume that the elucidation of the mechanisms responsible for these adaptations may contribute to a better understanding of the neural bases of drug addiction (Robinson and Berridge, 2000; White and Kalivas, 1998; Hyman and Malenka, 2001; Everitt and Wolf, 2002).

One of the most studied consequences of the repeated exposure to addictive drugs is represented by a persistent hypersensitivity to their psychomotor activating effects, a phenomenon known as psychomotor sensitization (Robinson and Becker, 1986; Stewart and Badiani, 1993; Van-

*Correspondence: Professor A Badiani, Department of Human Physiology and Pharmacology, University of Rome Sapienza, 5 Piazzale Aldo Moro, Rome 185, Italy, Tel: + 3906 499| 2499, Fax: + 3906 499| 2499, E-mail: aldo.badiani@uniromal.it

Received 12 September 2006; revised 10 January 2007; accepted 12 January 2007 derschuren and Kalivas, 2000). We have previously shown that the development of psychomotor sensitization to amphetamine, cocaine, and morphine is powerfully modulated by environmental context (for a review, see Badiani and Robinson, 2004). In particular, we have reported that low doses of amphetamine (Crombag et al, 1996; Browman et al, 1998b; Fraioli et al, 1999; Ostrander et al, 2003), cocaine (Badiani et al, 1995a; Browman et al, 1998a), or morphine (Badiani et al, 2000; Paolone et al, 2003) can induce robust psychomotor sensitization when administered in association with exposure to a novel environment but not when administered in the home cage. Also the ability of these drugs to induce the expression of the immediate early gene c-fos in the striatal complex and in other brain areas has been shown to be under the modulatory control of environmental context (Badiani et al, 1998, 1999; Uslaner et al, 2001a, b; Day et al, 2001; Ostrander et al, 2003; Ferguson et al, 2004). These findings indicate that pharmacological and non-pharmacological factors interact in producing drug-induced neurobehavioural plasticity (Badiani and Robinson, 2004). 
The goal of the present paper was to investigate the role of environmental context and drug history in modulating the neurobehavioral response to heroin. We studied the locomotor-activating effects of heroin in male rats that had previously received repeated administrations of either saline or heroin under different environmental conditions. In the same animals, we also studied the expression of the Fos protein (the protein encoded by c-fos) in the cortex and in the striatal complex, using immunohistochemistry. The transcription factor Fos is thought not only to be an indicator of neuronal activity (Hughes and Dragunow, 1995; Harlan and Garcia, 1998), but also to represent an important initial step in mediating drug-induced neuroplasticity (Hyman and Malenka, 2001; Nestler, 2001; Ujike et al, 2002).

\section{MATERIALS AND METHODS}

\section{Animals}

Forty male Sprague-Dawley rats (Harlan Italy, San Pietro al Natisone, UD, Italy), weighing 200-225 g upon arrival, were used in this study. Rats were individually housed in the cages described in the following section, with ad libitum access to food and water, under a $10 \mathrm{~h}$ light $/ 14 \mathrm{~h}$ dark cycle (lights on at 07:00 h). All rats were housed and tested in the same dedicated animal room throughout the experiment. This was carried out to minimize all environmental manipulations that might alter drug effectiveness (except, of course, for environmental 'novelty'). All procedures were in accordance with the Italian Law on Animal Research (DLGS 116/92) and the guidelines for the care and use of laboratory animals issued by Italian Ministry of Health.

\section{Procedures}

Thirty-two rats were used to generate both behavioral and immunohistochemistry data. As detailed below, these rats received repeated treatments with saline or heroin and were then challenged with heroin: saline-home $(n=8)$, salinenovelty $(n=8)$, heroin-home $(n=8)$, and heroin-novel $(n=8)$ groups. Two additional groups were used as control groups for the immunohistochemistry data: control-home $(n=4)$ and control novelty groups $(n=4)$.

Housing conditions. The rats were assigned to one of two testing conditions: home or novelty. The rats in the home condition were housed in transparent plastic cages $(40 \mathrm{~cm}$ length, $24.5 \mathrm{~cm}$ width, and $18 \mathrm{~cm}$ height) with stainless-steel tops and flat bottoms covered with ground corncob bedding. Home rats were left in these cages for the entire duration of the experiment and there they received the treatments (see below). That is, for the home rats the drug environment was also the home cage. The rats in the novelty condition were housed in hanging cages made of transparent plastic ( $25 \mathrm{~cm}$ length, $19.5 \mathrm{~cm}$ width, and $15 \mathrm{~cm}$ height) with stainless steel tops and grid floors. Plastic trays covered with pine wood shaving were placed under the grid floors. Novelty rats were kept in these cages for the entire duration of the experiment except during the daily test sessions when they were transferred to test cages identical to those of the home rats where they receive their drug treatments. In summary, the drug environment was physically identical (including the presence of food and water) for all rats but for some animal this was also the home cage whereas for other animals it represented a distinct and, at least initially, novel environment. Notice that the term 'novelty' is used in an operational sense to designate the testing conditions described above and does not imply that the testing environment remains cognitively novel for the rats throughout the experiment. Henceforth, the terms novel or novelty (without quotations marks) are used either as a group label or to indicate the exposure to the test environment for the first time (either in the present study or in earlier reports).

Repeated treatment (days 1-7). After 1 week of acclimatization to the housing conditions described above the rats underwent a repeated treatment phase. Every day (at 14:00 h) for 7 days, some rats received an intraperitoneal (i.p.) injection ( $1 \mathrm{ml} / \mathrm{kg}$ body weight) of either saline $(0.9 \%$ $\mathrm{NaCl})$ or heroin chlorohydrate $(1.0 \mathrm{mg} / \mathrm{kg}$ body weight $)$ dissolved in saline. Preliminary experiments had shown that this dose of heroin produces negligible locomotor activity per se but can serve as a threshold dose to induce sensitization under the 'novelty' conditions described above. After $120 \mathrm{~min}$ the rats of the novelty groups were returned to their home cages (see above).

Challenge (day 15). After the last injection of the repeated treatment all animals were left undisturbed (except than for the husbandry routine and the weighing procedures) for 7 days. The rats of the saline-home, saline-novelty, heroinhome, and heroin-novel groups were then administered an i.p. injection of $1.0 \mathrm{mg} / \mathrm{kg}$ of heroin, under the respective home or 'novelty' condition, and their locomotor activity was quantified by counting the number of crossovers from one side of the cage to the other, along the major axis. At the same time, the rats of the control-home and control-novelty groups received saline but their behavior was not recorded.

\section{Immunohistochemistry}

Two hours after the treatment all rats were killed by decapitation and their brains were excised and placed in ice-cooled $10 \%$ neutral-buffered formalin solution. Two hours later, formalin was renewed and fixation continued overnight at $4^{\circ} \mathrm{C}$. Fixed brains were cryoprotected in phosphate-buffered $30 \%$ sucrose solution for $48-72 \mathrm{~h}$ at $4{ }^{\circ} \mathrm{C}$ and then frozen with dry ice and cut in $40 \mu \mathrm{m}$ coronal sections using a sliding microtome. A series of sections were processed for Fos immunostaining and the number of positive neurons was counted in the caudate, in the shell and core of the nucleus accumbens, and in the barrel field of the primary somatosensory cortex. Previous studies indicated that these areas exhibit differential drug-induced Fos-mRNA expression as a function of environmental context (Badiani et al, 1998; Uslaner et al, 2001a, b). Notice that we used the term caudate to indicate the same structure that other authors call caudate-putamen (see Riedel et al, 2002).

Unless otherwise stated, $0.1 \mathrm{M}$ phosphate buffer, $\mathrm{pH}$ 7.4, plus $0.3 \%$ Triton X-100 (Sigma) was used for both chemicals 
dilution and rinsing. Floating Sections were first treated for $30 \mathrm{~min}$ with $2 \%$ hydrogen peroxide, then rinsed and incubated overnight at $4{ }^{\circ} \mathrm{C}$ in primary antibody (polyclonal IgG raised in rabbit against residues 4-17 of the human Fos, PC-38, Oncogene) diluted 1:20000 and supplemented with $5 \%$ normal goat serum (Vector Laboratories). Sections were then rinsed, incubated for $2 \mathrm{~h}$ in biotinylated secondary antibody diluted 1:500 (Vector Laboratories), rinsed again and incubated for $1 \mathrm{~h}$ in avidin-biotin-peroxidase complex (Vectastain Elite ABC Kit, Vector Laboratories) diluted 1:500. After new rinsing, tissue-bound peroxidase was revealed by incubating sections in chromogenic substrate solution prepared according to the manufacturer's instructions (Sigma Fast DAB with metal enhancer). Finally, sections were rinsed in $5 \mathrm{mM}$ TBS pH 8.0 (Sigma), mounted on positively charged slides (Superfrost, Menzel and Glaser), dehydrated, cleared, and coverslipped with Clarion mounting medium (Sigma). Sections from all treatment groups were processed in a single experiment to avoid batch-dependent variability.

Visual examination and digital imaging of immunoreacted sections were performed with a Zeiss Axiophot light transmission microscope equipped with a CoolSnap CCD camera. Densities of Fos-immunoreactive nuclei were automatically evaluated using the public domain image analysis software Image (NIMH) as described previously by Conversi et al (2004). Primary somatosensory cortex layers were delineated by Nissl's staining of adjacent sections.

\section{Statistical Analysis}

Locomotor-activity data of the repeated treatment phase were analyzed using a three-way analyses of variance (ANOVA) for the factors environment (two levels, home, and novelty) and pretreatment (two levels: saline and heroin), and with repeated measures on the factor session (seven levels, one for each test session).

Locomotor activity and Fos data of the challenge day were analyzed using two-way analyses of variance (ANOVA) for the factors environment (two levels, home and novelty) and pretreatment (two levels: saline and heroin). The data from the caudate were also analyzed using a three-way analyses of variance (ANOVA) for the factors environment, pretreatment, and region. Post hoc comparisons were conducted using Fisher's PLSD tests.

The net effect of heroin on Fos expression (Figures 2-4) was calculated by subtracting the mean value of Fos expression in the appropriate control group (see Table 1).

Multiple regression analysis (see Table 2) was conducted using a forward procedure with a maximum of three variables (because it is thought that the optimal ratio between number of observations and number of independent variables should be at least 10).

\section{RESULTS}

\section{Locomotor Activity}

As expected, the first injection of heroin had negligible effect on locomotor activity, whereas exposure to novelty induced a period of hyperactivity (Figure 1, top left panel). With repeated exposures, however, the activating effects of
Table I Fos Expression (Nuclei/ $100 \mu \mathrm{m}^{2}$ ) after an i.p. Injection of Saline Administered, under Either Home or 'Novelty' Conditions, 7 Days after the End of a Repeated Treatment with Saline (See Text)

\begin{tabular}{lccc}
\hline Region & Control-home & Control-novelty & \\
\hline Barrel field cortex & & & \\
Layers II-III & $0.98 \pm 0.57$ & $89.22 \pm 14.15$ & $P<0.001$ \\
Layer IV & $0.59 \pm 0.59$ & $\mid 17.26 \pm 15.59$ & $P<0.00$ I \\
Layers V-VI & $2.03 \pm 0.9 \mid$ & $23.31 \pm 3.05$ & $P<0.001$
\end{tabular}

\section{Caudate}

$\begin{array}{llll}\text { Dorso-medial } & 3.65 \pm 0.57 & 6.27 \pm 1.30 & P=0.115 \\ \text { Ventro-medial } & 0.95 \pm 0.24 & 1.66 \pm 0.55 & P=0.286 \\ \text { Dorso-lateral } & 0.03 \pm 0.03 & 0.14 \pm 0.11 & P=0.393 \\ \text { Ventro-lateral } & 0.00 \pm 0.00 & 0.00 \pm 0.00 & \\ \text { Postero-dorsal } & 6.74 \pm 1.11 & 7.26 \pm 2.39 & P=0.849 \\ \text { Postero-ventral } & 6.78 \pm 1.39 & 11.22 \pm 2.49 & P=0.161\end{array}$

Nacc

$\begin{array}{llll}\text { Shell } & 0.92 \pm 0.21 & 3.61 \pm 0.48 & P=0.006 \\ \text { Core } & 0.78 \pm 0.22 & 2.95 \pm 0.46 & P=0.002\end{array}$

'novelty' in saline-injected rats underwent habituation, whereas the activity levels of heroin-injected rats remained more or less stable (data not shown). Indeed, by day 7 there were no environment-dependent differences in the activity of saline-injected rats whereas heroin-induced hyperactivity was evident only in the rats that had received the treatment in a 'novel' environment (Figure 1, bottom left panel). The ANOVA indicated a significant effect of environment $\left(\mathrm{F}_{1,28}=8.00 ; P<0.008\right)$ but not of treatment $(P=0.31)$, and no environment $\times$ treatment interaction $(P=0.69)$. The ANOVA indicated a significant effect of environment $\left(\mathrm{F}_{1,28}=34.77 ; P<0.0001\right)$, treatment $\left(\mathrm{F}_{1,28}=10.01\right.$; $P=0.0002)$ and session $\left(\mathrm{F}_{6,168}=3.24 ; P=0.005\right)$, as well as significant environment $\times$ treatment $\quad\left(\mathrm{F}_{1,28}=6.17\right.$; $P=0.019)$, session $\times$ environment $\left(\mathrm{F}_{6,168}=2.87 ; P=0.011\right)$, session $\times$ environment $\times$ treatment $\left(\mathrm{F}_{6,168}=2.52 ; P=0.023\right)$ but not session $\times$ treatment $(P=0.017)$ interactions. The ANOVA also indicated a simple interaction effect for environment $\times$ treatment on day $7(P=0.025)$ but not on day $1(P=0.87)$.

These results suggest that sensitization to the locomotoractivating effects of heroin developed when the treatment was administered under 'novelty' conditions but not when administered at home. This conclusion is supported by results obtained on the challenge day, when all groups received an i.p. injection of $1.0 \mathrm{mg} / \mathrm{kg}$ after 7 days of withdrawal from any treatment (Figure 1, bottom right panel). The ANOVA indicated a significant effect of environment $\left(\mathrm{F}_{1,28}=17.26 ; P<0.001\right)$ and of pretreatment $\left(\mathrm{F}_{1,28}=7.12 ; P=0.012\right)$, with an environment $\times$ pretreatment interaction approaching significance $\left(\mathrm{F}_{1,28}=3.86\right.$; $P=0.059)$. Post hoc tests showed a significant effect of pretreatment for the novelty $(P<0.0001)$ but not for the home condition $(P=0.62)$, confirming that locomotor sensitization developed only when repeated heroin was 
Table 2 Multiple Regression, Using a Forward Procedure, of Locomotor Activity Scores on Fos Protein Levels for Different Subsets of Brain Regions

Coefficients

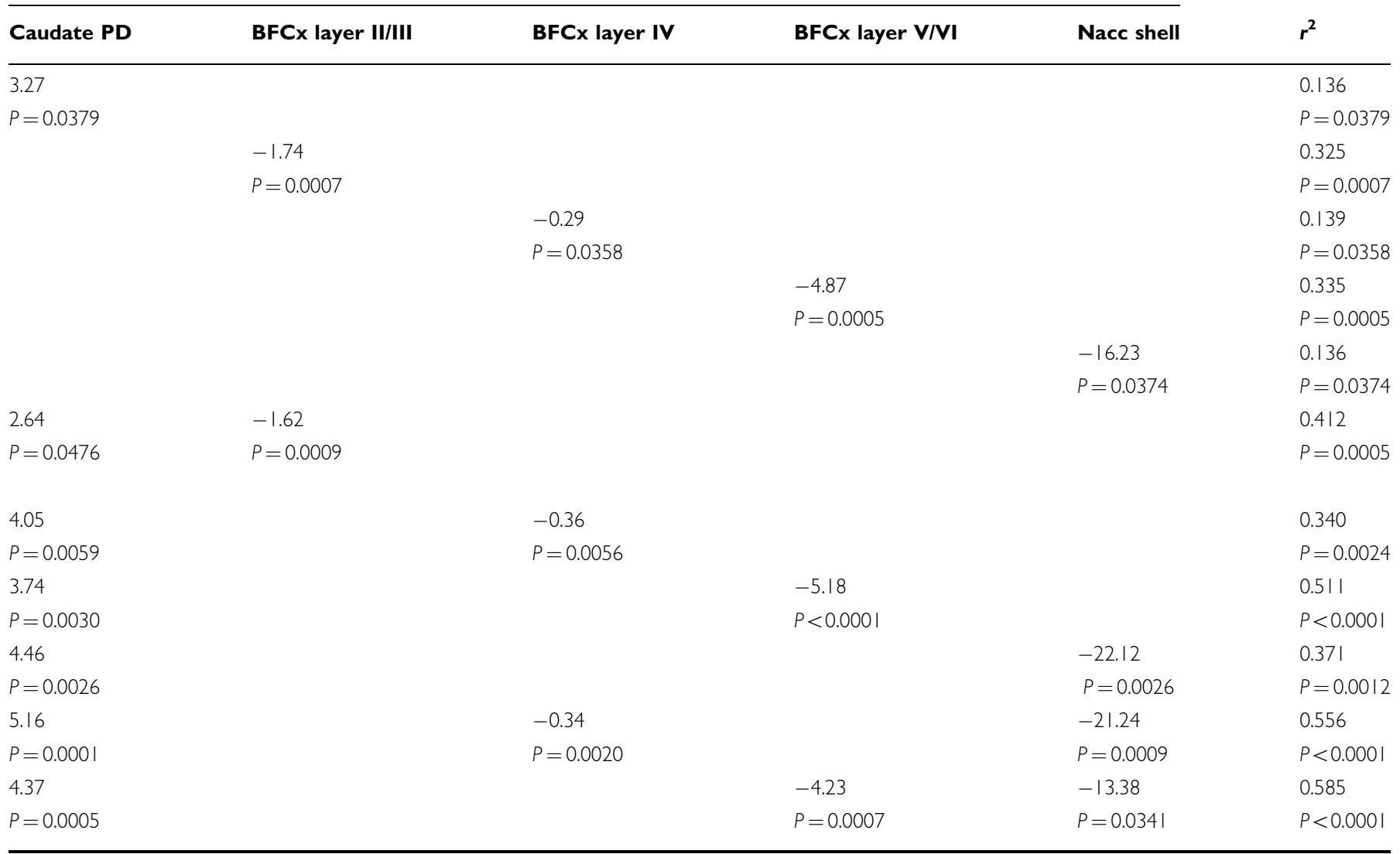

administered under 'novelty' conditions. The ANOVA also indicated a significant effect of time $\left(\mathrm{F}_{3,84}=6.9 ; P<0.001\right)$, and significant time $\times$ environment $\left(\mathrm{F}_{3,84}=4.67 ; P<0.01\right)$ and time $\times$ pretreatment $\left(\mathrm{F}_{3,84}=4.12 ; P<0.01\right)$ interactions, with a time $\times$ environment $\times$ pretreatment approaching significance $\left(\mathrm{F}_{3,84}=2.39 ; P=0.074\right)$.

\section{Fos Expression}

Effect of 'novelty' on Fos Expression. As illustrated in Table 1, exposure to 'novelty' enhanced Fos protein expression in the cortex (particularly in layers II/III and IV) and in the nucleus accumbens but not in the caudate.

Heroin-induced Fos expression in the nucleus accumbens. The top panels of Figure 2 illustrate the net effect of heroin on Fos protein expression in the shell and the core of the nucleus accumbens. It can be seen that environmental 'novelty' reduced Fos expression in the shell, as indicated by a significant effect of environment in the shell $\left(\mathrm{F}_{1,28}=8.26\right.$; $P=0.008)$ but not in the core $(P=0.149)$. Furthermore, there was a borderline effect of pretreatment in the shell $\left(\mathrm{F}_{1,28}=3.08 ; P=0.090\right)$ but not in the core $(P=0.70)$, and no environment $\times$ pretreatment interaction in either area.

Heroin-induced Fos expression in the caudate. Overall, heroin-induced Fos expression in the caudate was enhanced by environmental 'novelty' $\left(\mathrm{F}_{1,28}=14.99 ; P=0.0006\right)$ and reduced by repeated heroin pretreatments $\left(\mathrm{F}_{1,28}=6.13\right.$; $P=0.020)$. However, there were important regional differences in these effects, as indicated by environment $\times$ region $\left(\mathrm{F}_{1,140}=9.64 ; P<0.0001\right)$, pretreatment $\times$ region $\left(\mathrm{F}_{1,140}=\right.$ 4.54; $P=0.0007)$, and environment $\times$ pretreatment $\times$ region $\left(\mathrm{F}_{1,28}=5.04 ; P=0.0003\right)$ interactions.

The bottom panels of Figure 2 illustrate the net effect of heroin on Fos protein expression in the anterior caudate, between +1.7 and $-0.3 \mathrm{~mm}$ from bregma. Fos density was much higher in the medial caudate than in the lateral caudate, where very few immunoreactive nuclei were evident (notice the different unit values for the $y$ axes of the various panels). There was a significant effect of 'novelty' in the dorso-medial $\left(\mathrm{F}_{1,28}=6.22 ; P=0.019\right)$, ventro-medial $\left(\mathrm{F}_{1,28}=5.77 ; P=0.023\right)$, and in the ventrolateral $\left(\mathrm{F}_{1,28}=5.57 ; P<0.025\right)$ quadrants, but not in the dorso-lateral quadrant $(P=0.186)$. There was no significant effect of pretreatment or environment $\times$ pretreatment interaction in any quadrant $(P$ 's $<0.114)$ except for the ventrolateral caudate $\left(\mathrm{F}_{1,28}=5.57 ; P=0.025\right)$.

Figure 3 illustrates the net effect of heroin on Fos protein expression in the posterior caudate, between -0.8 and $-1.3 \mathrm{~mm}$ from bregma. In the postero-dorsal caudate, there was a significant effect of environment $\left(F_{1,28}=10.93\right.$; $P=0.003)$ but no effect of pretreatment $(P=0.113)$ nor environment $\times$ pretreatment interaction $(P=0.356)$. In the 

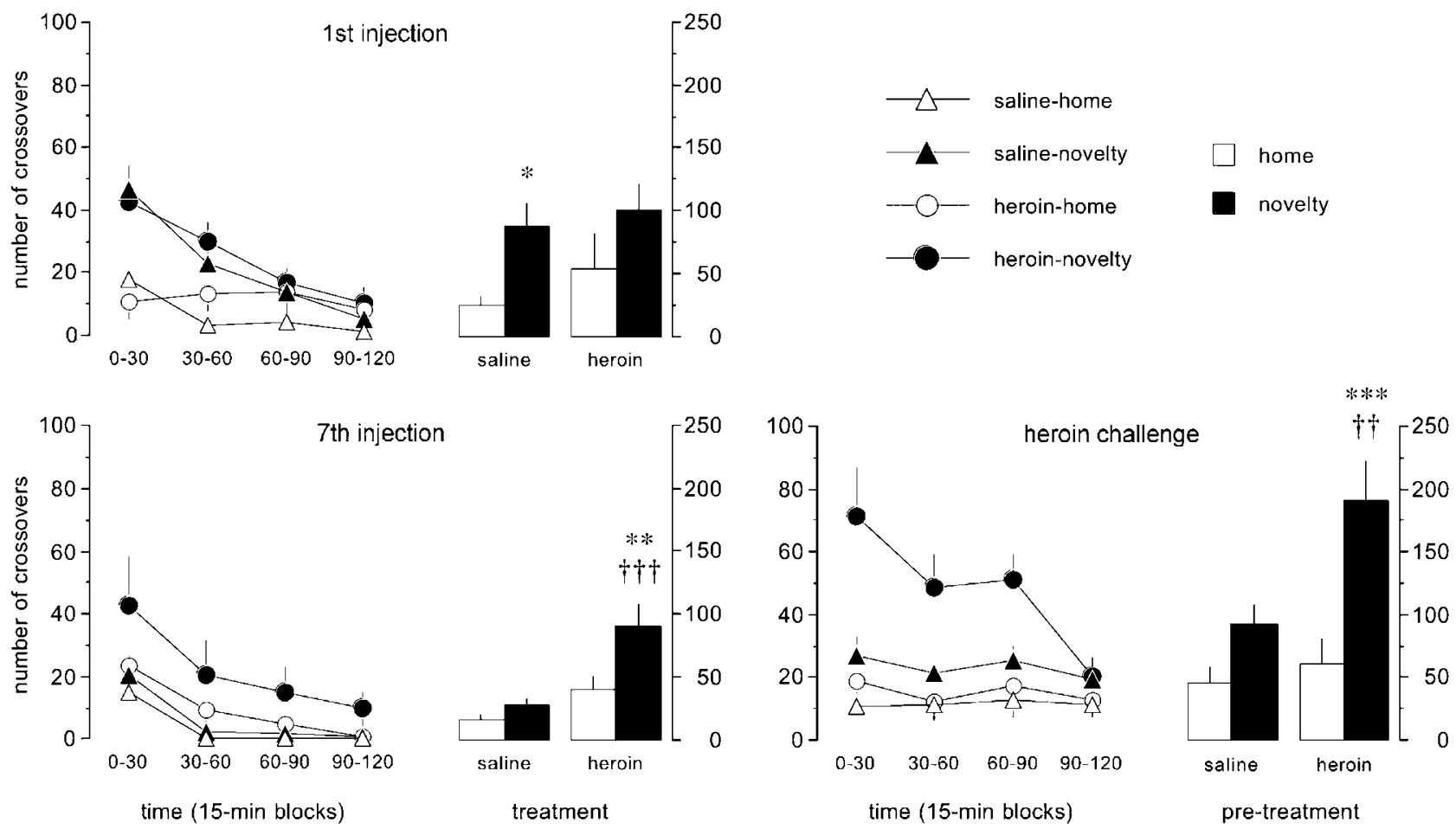

Figure I Locomotor activity (mean number of crossovers \pm SEM) after the first and the seventh i.p. injection of a repeated treatment with either saline $1.0 \mathrm{mg} / \mathrm{kg}$ of heroin (left hand panels) and on the challenge day, when all rats received $1.0 \mathrm{mg} / \mathrm{kg}$ of heroin 7 days after the end of the repeated treatment phase (right hand panels). The treatments were administered under either home (saline-home and heroin-home groups) or 'novelty' conditions (salinenovelty and heroin-novelty groups). The right-hand panel shows total activity during the I 20 min session. $\dagger \dagger$, and $\dagger \dagger \dagger$ indicate $P<0.0 I$, and $P<0.00 I$ vs the respective saline-pretreated group. $*$, **, and $* * * *$ indicate $P<0.05, P<0.01$, and $P<0.00$ I vs the respective home group.

postero-ventral caudate, there was a significant effect of environment $\left(\mathrm{F}_{1,28}=12.28 ; P=0.002\right)$ and of pretreatment $\left(\mathrm{F}_{1,28}=5.91 ; P=0.022\right)$, and a significant environment $\times$ pretreatment interaction $\left(\mathrm{F}_{1,28}=4.82 ; P=0.037\right)$. Furthermore, post hoc tests showed significant effect of environment for the saline-pretreatment $(P<0.001)$, but not for the heroin-pretreatment level $(P>0.36)$, as well as an effect of pretreatment for the novelty $(P<0.01)$ but not for the home level $(P>0.87)$.

Heroin-induced Fos expression in the primary somatosensory cortex. Figure 4 illustrates the net effect of heroin on Fos protein expression in the primary somatosensory cortex, between -0.3 and $-1.3 \mathrm{~mm}$. from bregma (barrel field cortex). Heroin-induced Fos levels in layers II/III were lower in the novelty than in the home group and this effect was much greater in the animals pre-exposed to heroin. The ANOVA yielded in fact a significant effect of environment $\left(\mathrm{F}_{1,28}=5.91 ; P=0.022\right)$ and of pretreatment $\left(\mathrm{F}_{1,28}=65.27\right.$; $P<0.0001)$, and an environment $\times$ pretreatment interaction $\left(\mathrm{F}_{1,28}=10.67 ; P=0.003\right)$. A similar pattern was evident in layers V/VI, where there was a significant effect of environment $\left(\mathrm{F}_{1,28}=16.35 ; P=0.004\right)$ and of pretreatment $\left(\mathrm{F}_{1,28}=4.62 ; \quad P=0.040\right)$, and an environment $\times$ pretreatment interaction $\left(\mathrm{F}_{1,28}=8.77 ; P=0.006\right)$. By contrast, in layer IV 'novelty' had opposite effects on heroin-induced Fos expression as a function of pretreatment: in salinepretreated rats there was an increase relative to the home group whereas in the heroin-pretreated rats there was a decrease. The ANOVA indicated a significant effect of pretreatment $\left(\mathrm{F}_{1,28}=138.67 ; P<0.0001\right)$, a borderline effect of environment $\left(\mathrm{F}_{1,28}=4.00 ; P=0.055\right)$, and an environment $\times$ pretreatment interaction $\left(\mathrm{F}_{1,28}=189.00 ; P<0.0001\right)$. Owing to the fact that Fos levels in layer IV were much greater than in layers II/III and V/VI, the overall pattern of Fos expression in the barrel field cortex mirrored the pattern of layer IV, with a significant effect of pretreatment $\left(\mathrm{F}_{1,28}=71.13 ; \quad P<0.0001\right) \quad$ but not of environment $(P=0.107)$, and an environment $\times$ pretreatment interaction $\left(\mathrm{F}_{1,28}=100.70 ; P<0.0001\right)$.

Relationship between heroin-induced Fos expression in the primary somatosensory cortex and that in the nucleus accumbens and in the caudate. Fos expression in the nucleus accumbens was not correlated with Fos expression in any layer of the somatosensory cortex either in the home $(r s<0.29)$ or in the 'novelty' $(r s<0.05)$ condition.

A correlation between Fos expression in the barrel field cortex and that in the caudate, as a function of cortical layer and caudate region, was found in the rats that had received heroin under 'novelty' conditions. In these animals, Fos protein levels of layers V/VI were strongly related with those of the dorso-medial, ventro-medial, dorso-lateral, and postero-dorsal caudate $(r s=0.85,0.82,0.78$, and 0.72 , respectively), and more loosely to those of the ventrolateral and postero-ventral caudate $(r s=0.52$ and 0.63 , respectively). Somewhat similar correlations were found between the same regions of the caudate and layers II/III ( $r s=0.73,0.72,0.64,0.71,0.65$, and 0.65 , respectively), which is not surprising given that Fos levels of layers II/III were correlated with those of layers V/VI $(r=0.86)$. In 


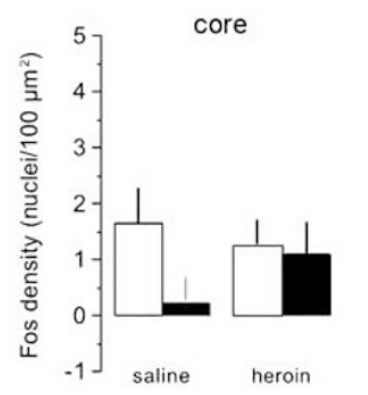

pre-treatment

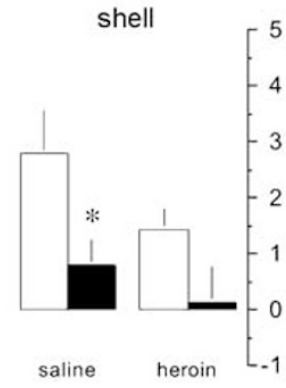

pre-treatment

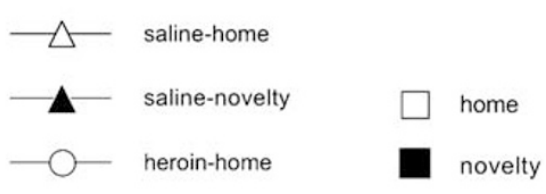

- heroin-novelty

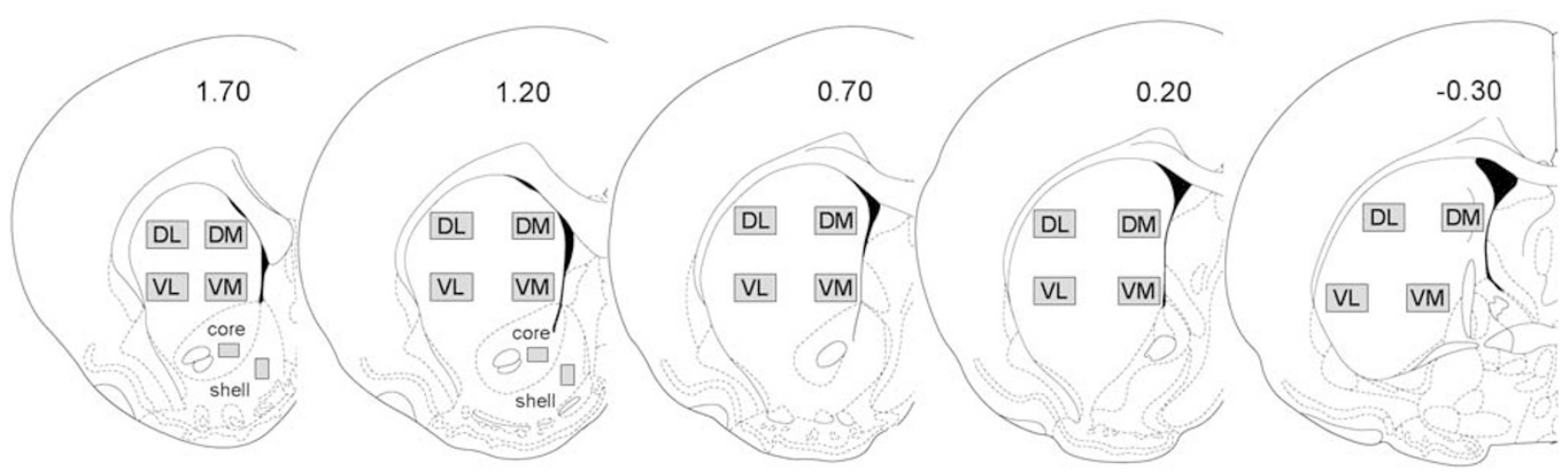

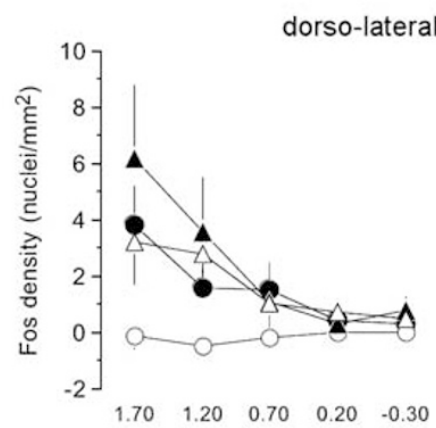
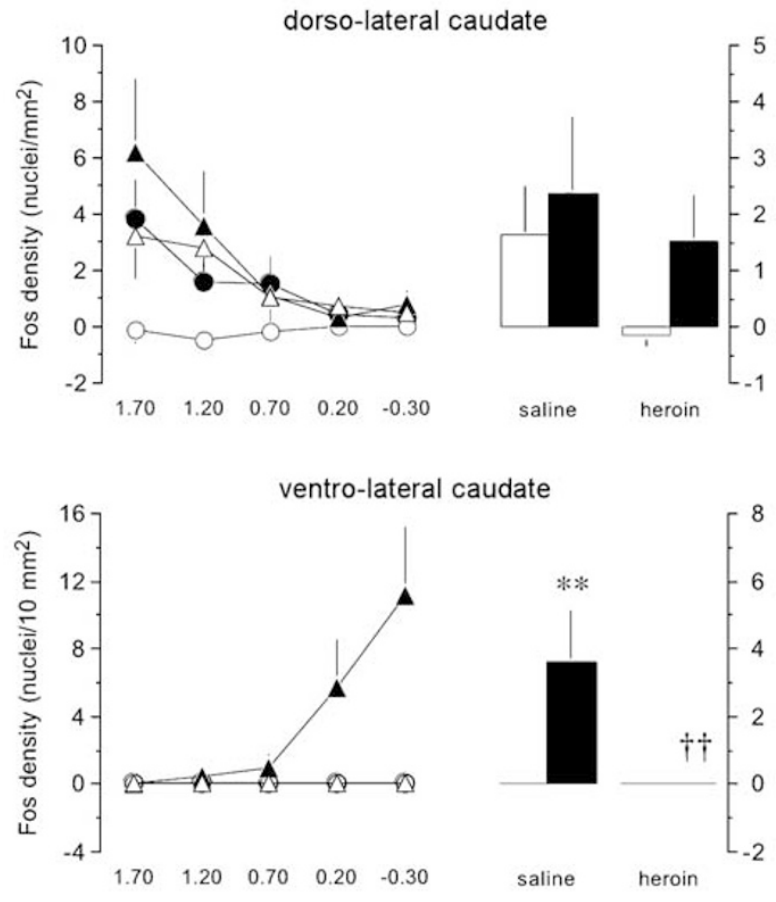

distance from bregma $(\mathrm{mm})$

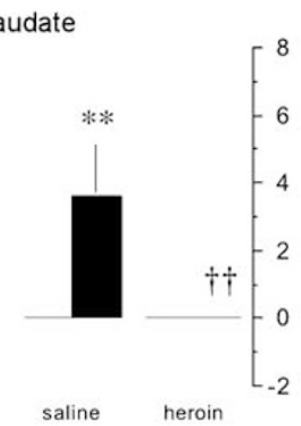

pre-treatment
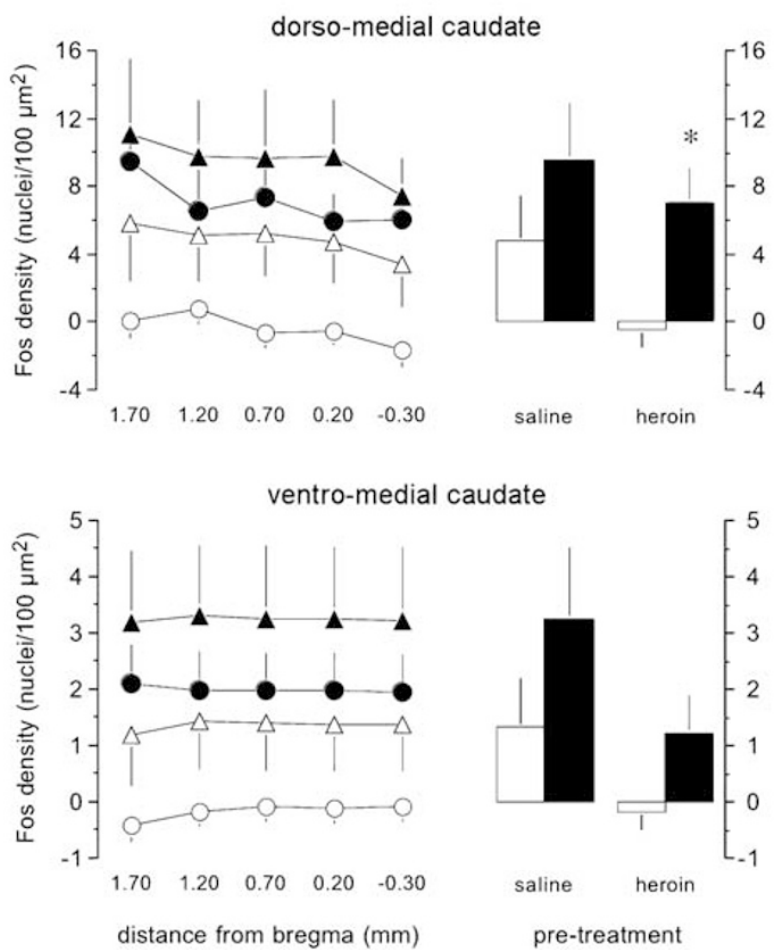

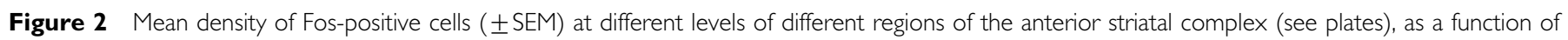
pretreatment and of environmental condition. Data are expressed as net values after subtracting the mean Fos value of the respective saline-pretreated group. Notice the different unit values of the $y$ axes for the various panels plates were taken from the atlas by Paxinos and Watson (I997). $\dagger \dagger$ indicates $P<0.0$ I relative to the appropriate saline-pretreated group. $*$ and $* *$ indicate $P<0.05$ and $P<0.0$ I, respectively, relative to the appropriate home group. 
Net Fos expression in the posterior caudate
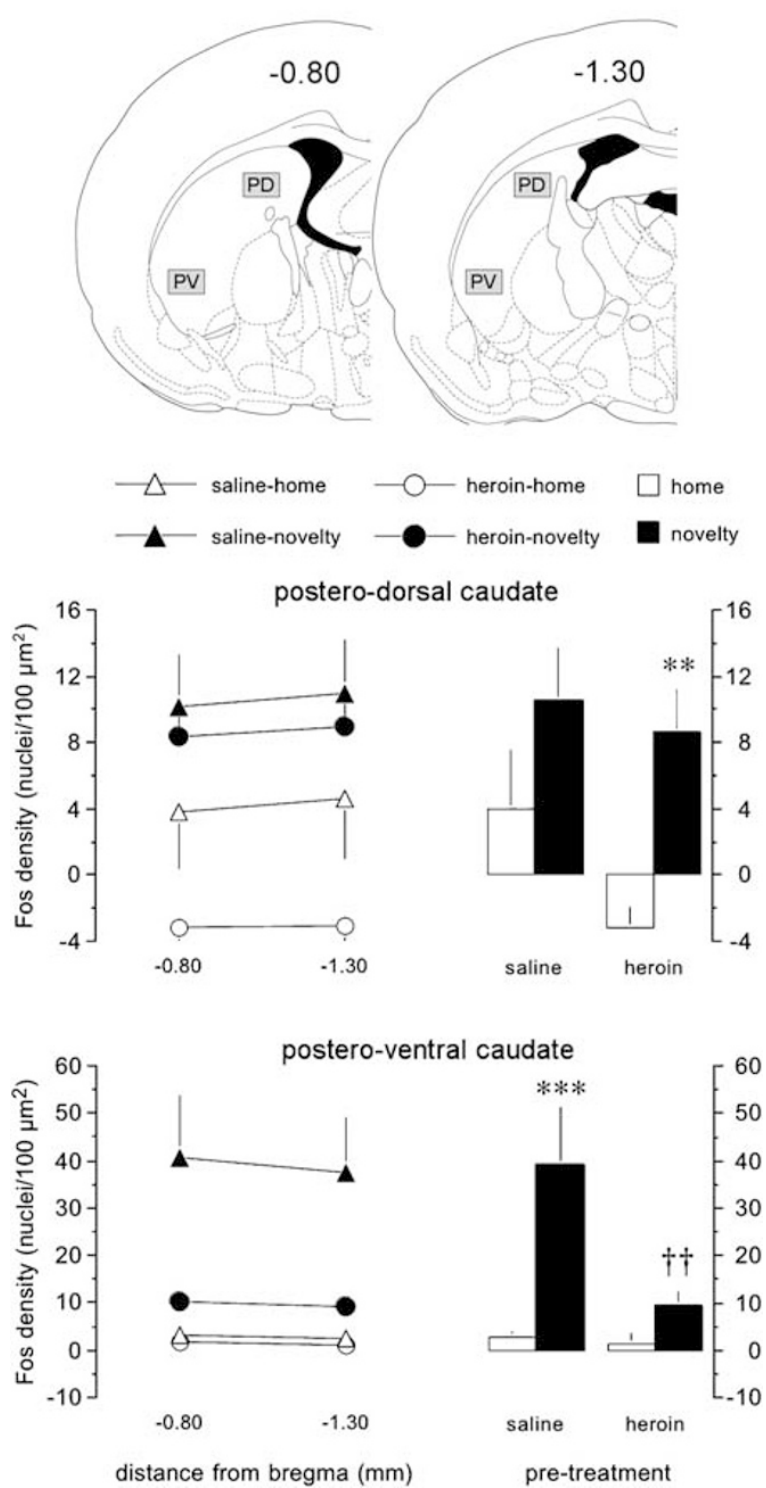

Figure 3 Mean density of heroin-induced Fos-positive cells $( \pm S E M)$ at different levels of the posterior caudate (see plates), as a function of pretreatment and of environmental condition. Data are expressed as net values after subtracting the mean Fos value of the respective salinepretreated group. Plates were taken from the atlas by Paxinos and Watson (1997). $\dagger$ indicates $P<0.0$ I relative to the appropriate saline-pretreated group. $* *$ and $* * *$ indicate $P<0.01$ and $P<0.001$, respectively, relative to the appropriate home group.

contrast, Fos levels of layers IV were correlated with those of the ventro-lateral and postero-ventral caudate $(r s=0.64$ and 0.64 , respectively) but not with those of the dorsomedial, ventro-medial, dorso-lateral, and postero-dorsal caudate $(r s<0.37)$. Finally, no correlation in Fos levels was found between any region of caudate and any layer of the barrel field cortex $(r s<0.35)$ in the home rats.

\section{Relationship Between Activity and Fos Expression}

Regression of locomotor-activity scores on Fos protein levels was relatively poor for each of the eleven brain regions analyzed here and reached significance only in five of them: postero-dorsal caudate, layers II/III, IV, and V/VI of the barrel field cortex, and shell of the nucleus accumbens. More satisfactory linear prediction equations were obtained by means of multiple regression analysis (Table 2). Thus, it appears that Fos protein levels in the postero-dorsal caudate, in the barrel field cortex and in the shell reflect important information concerning how environmental context and drug history interacted in modulating heroin-induced activity. The combined predictive power of these three regions was even greater when multiple regression analysis was conducted separately for each group of animals, accounting for about $90 \%$ of the total variance in locomotor-activity scores (Figure 5).

\section{DISCUSSION}

We report here that (1) repeated i.p. administrations of a relatively low dose of heroin $(1 \mathrm{mg} / \mathrm{kg}$, i.p. $)$ in the rat induced psychomotor sensitization only when the treatment was administered in a relatively 'novel' environment (ie, a unique test environment distinct from the home cage) but not when the same treatment was administered in the home cage; (2) environmental 'novelty' facilitated heroin-induced Fos expression in the caudate, particularly in its most caudal regions; (3) environmental context also modulated heroin-induced Fos expression in the nucleus accumbens and in the neocortex; (4) repeated exposures to heroin dramatically altered its effects on Fos expression in the caudate and in the neocortex; and (5) Fos protein levels in the postero-dorsal caudate, in the shell of the nucleus accumbens, and in the barrel field cortex predicted most of the variance in heroin-induced locomotor-activity scores.

\section{Environmental Modulation of Heroin-Induced Locomotor Sensitization}

The present study confirms earlier reports that repeated exposures to heroin can induce sensitization to its locomotor-activating effects (Marinelli et al, 1998; De Vries et al, 1998). Most importantly, we found that the ability of heroin to induce psychomotor sensitization is powerfully modulated by the environment in which the treatment is administered. Although two groups of rats received the same number of injections of the same dose of heroin in the same physical environment, locomotor sensitization was evident only in the group in which the test environment was distinct from the home cage. Similar results have been previously reported for amphetamine (Badiani et al, 1995a, 1997; Crombag et al, 1996; Browman et al, 1998a; Fraioli et al, 1999; Ostrander et al, 2003), cocaine (Badiani et al, 1995b; Browman et al, 1998b), and morphine (Badiani et al, 2000; Paolone et al, 2003).

It should be noticed that although it is commonly thought that heroin is just a pro-drug of heroin there compelling preclinical and clinical evidence that the pharmacological actions of heroin are different from those of morphine. For instance, heroin is greatly preferred to morphine as an analgesic even in the pediatric setting (Kendall et al, 2001). Moreover, under controlled conditions and at equipotent doses, heroin is preferred to morphine by heroin users, 

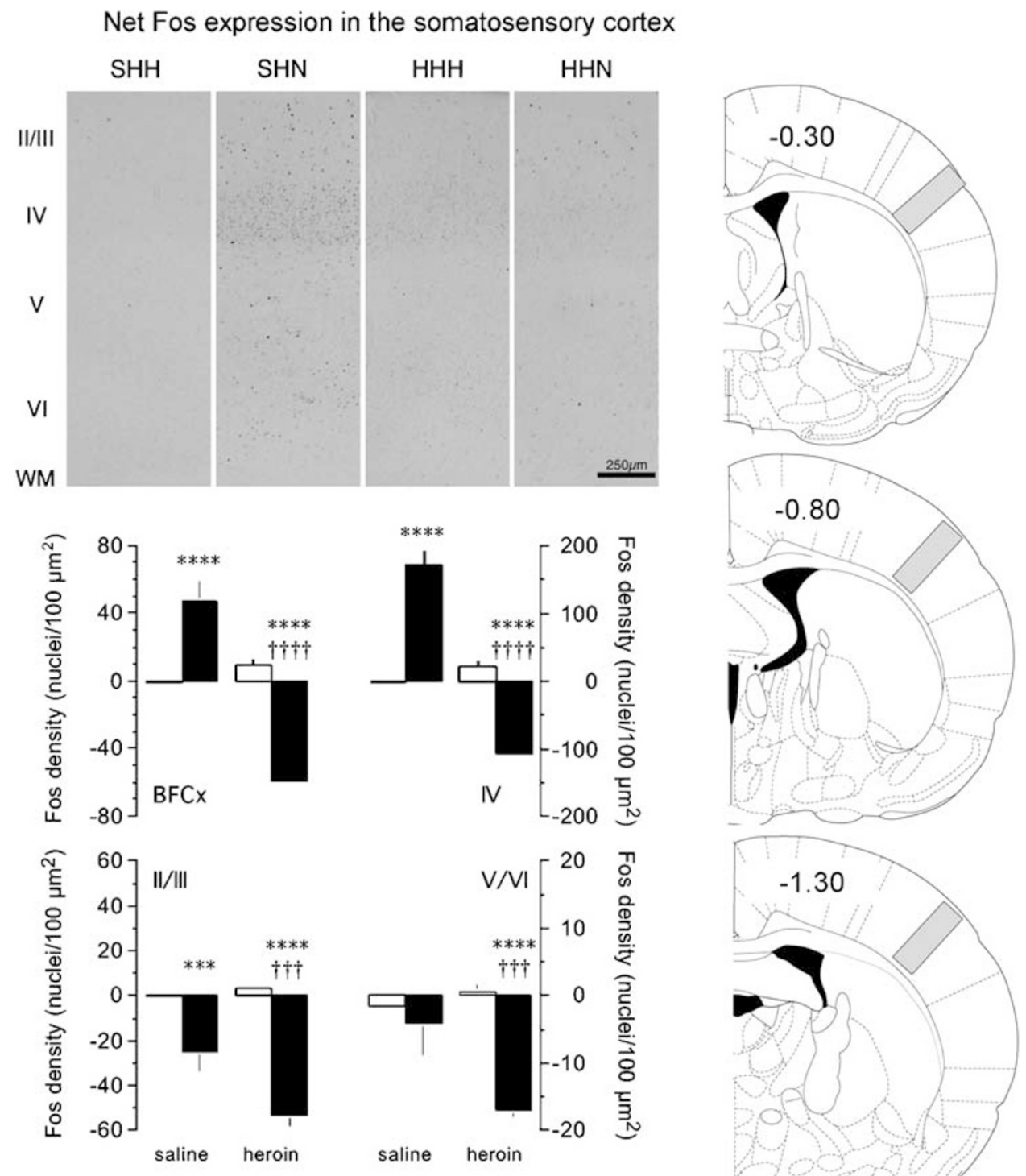

pre-treatment

pre-treatment

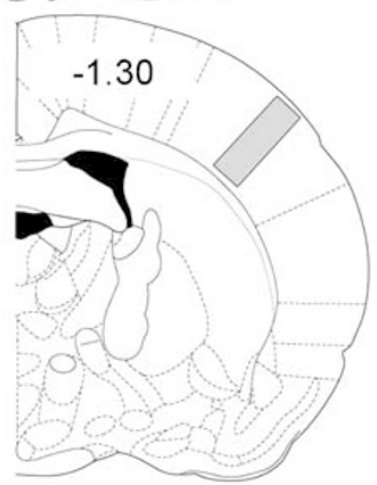

Figure 4 Mean density of heroin-induced Fos-positive cells $( \pm$ SEM) in the primary somatosensory cortex as a whole (BFCx) and in its different layers as a function of pretreatment and of environmental condition (white bars indicating the home groups and black bars indicating the novelty groups). Data are expressed as net values after subtracting the mean Fos value of the respective saline-pretreated group. Plates were taken from the atlas by Paxinos and Watson (1997). $\dagger \dagger \dagger$ and $+\dagger \dagger \dagger$ indicate $P<0.001$ and $P<0.000$, respectively, relative to the appropriate saline-pretreated group. $* * *$ and $* * * * *$ indicate $P<0.00$ I and $P<0.000$ I, respectively, relative to the appropriate home group.

being less aversive and more rewarding (Haemmig and Tschacher, 2001; Tschacher et al, 2003). These authors interpreted their findings as the consequence of different mechanisms of action of the two opioids (Tschacher et al, 2003). Indeed, heroin differs from morphine in its pattern of affinity for the opioid receptors. Rady et al (1991), using an experimental model of pain, found that heroin acted at supraspinal opioid receptors different from those activated by heroin. Pasternak and coworkers went further along this line and concluded that heroin and morphine exhibit preferential affinity for different subtypes of the mu opioid (MOP) receptor (for a review, see Pasternak, 2001). Finally, recent studies (Antonilli et al, 2003a, b, 2005) have shown that morphine and heroin also differ in their ability to alter the synthesis of morphine-3-glucuronide $v s$ morphine-6- glucuronide, (ie, of the inactive $v s$ the active metabolite of morphine; Schuller et al, 1999). Thus, the fact that environmental context altered in a similar manner the development of psychomotor sensitization to heroin and morphine is not as obvious as it may appear.

\section{Environmental Modulation of Heroin-Induced Fos Expression in the Striatal Complex}

Virtually all addictive drugs have been reported to enhance Fos expression in the striatal complex through the activation of the mesostriatal dopaminergic system (for a review, see Harlan and Garcia, 1998). The ability of morphine to induce Fos expression in the caudate, for example, has been shown to depend on its actions in the 


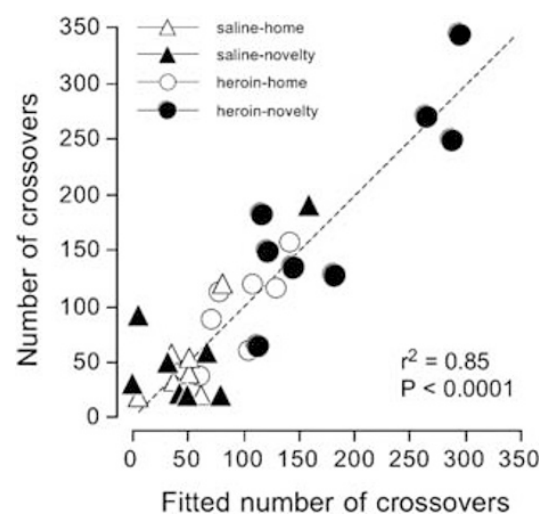

Figure 5 Regression of locomotor-activity scores over fitted values calculated with multiple regression analysis on the basis of the Fos data from the postero-dorsal caudate, layer VI of the barrel field cortex, and the shell of the nucleus accumbens (see text and Table 2).

ventral tegmental area and substantia nigra (Bontempi and Sharp, 1997), where it is known to produce a disinhibition of mesostriatal dopaminergic neurons (Moleman and Bruinvels, 1979; Matthews and German, 1984; Johnson and North, 1992; Devine et al, 1993). The caudate and the nucleus accumbens are thought to be implicated in both the psychomotor and the rewarding effects of heroin (Spyraki et al, 1983; Vaccarino et al, 1985; Vaccarino and Corrigall, 1987; Stewart and Vezina, 1988; Wise, 1989; Hutcheson et al, 2001; Shalev et al, 2002; Jacobs et al, 2004).

Earlier studies have shown that environmental novelty greatly enhances amphetamine- and cocaine-induced Fos mRNA expression throughout the caudate (Badiani et al, 1998; Uslaner et al, 2001a; Ostrander et al, 2003). We now report that also heroin-induced Fos expression in the caudate can be enhanced by 'novelty'. This interaction was particularly dramatic in the ventral portion in the posterior caudate, where net heroin-induced Fos expression in the novelty group was about 15 times that of the home group. We obtained similar results in an in situ hybridization study (manuscript in preparation) using very a low dose of heroin $(0.025 \mathrm{mg} / \mathrm{kg}$, i.v.).

Thus, it appears that the postero-ventral caudate is particularly implicated in the acute interaction between heroin and environment. This finding is in partial agreement with the results of earlier studies showing that also for amphetamine- and cocaine-induced Fos mRNA expression the modulatory effect of environment is greatest in the posterior caudate (Badiani et al, 1998; Uslaner et al, 2001a). In the case of amphetamine and cocaine, however, the potentiation of drug-induced Fos mRNA expression by 'novelty' was much greater in the dorsal portion than in the ventral portion of the posterior caudate (Ostrander et al, 2003). The reason for these regional differences in the modulatory actions of environment on the response to psychostimulants $v s$ heroin are not clear but may be related to a differential engagement of the neurons of the striatopallidal $v s$ the striato-nigral projection system. Indeed, environmental novelty has been shown to enhance amphetamine- and cocaine-induced Fos mRNA expression in both the striato-nigral neurons and the striato-pallidal neurons (Badiani et al, 1999; Uslaner et al, 2001b). In contrast, in a study limited to the postero-dorsal caudate (Ferguson et al,
2004), novelty exhibited opposite effects on morphineinduced Fos mRNA expression in these two subpopulations, increasing it (but only at high doses) in the striato-nigral neurons whereas reducing it in the striato-pallidal neurons. Thus, it is possible that the effects of 'novelty' described here were due to a selective enhancement of heroin-induced Fos expression in the striato-nigral neurons. Further studies using double in situ hybridization procedures are necessary to verify this hypothesis.

Heroin-induced Fos expression in the caudate was also a function of drug history. Overall, repeated exposures to heroin reduced its ability to induce Fos in the caudate but also in this case there were important environmental and regional differences. In particular, the interaction between environment and drug history had different consequences on heroin-induced Fos expression in the dorsal $v s$ the ventral caudate, particularly at the most posterior levels. In the postero-ventral caudate the facilitatory effect of 'novelty' in the 'novelty' group was maximal in the saline-pretreated animals whereas it was modest in the heroin-pretreated animals. By contrast, in the postero-dorsal caudate the modulatory effects of the environment was much greater in heroin-pretreated than in saline-pretreated animals. A somewhat similar pattern of Fos expression has been described previously for amphetamine (Ostrander et al, 2003). Thus, it is possible that the persistence of robust Fos expression in the dorsal caudate after repeated drug exposures is related to the modulatory effect of environment on drug-induced psychomotor sensitization.

Notice, however, that in the 'novelty' group there were no significant differences in heroin-induced Fos expression between saline-pretreated and heroin-pretreated rats. These results are in apparent contrast with the findings by Pontieri et al (1997) and D'Este et al (2002), who reported sensitization of heroin-induced Fos expression in the rat caudate. This discrepancy may be owing to the differences in heroin regimen between these earlier studies and the present study. During the repeated treatment phase, Pontieri, D'Este and colleagues injected high doses of heroin twice a day (for a total of $28-70 \mathrm{mg} / \mathrm{kg}$ over a 3-day period) using a subcutaneous route of administration, which certainly produced persistent high concentrations of heroin, morphine, and M6G. Intermittent vs continuous drug regimens may have very different consequences on brain and behavior (see Stewart and Badiani, 1993).

Heroin-induced Fos expression in the nucleus accumbens (particularly in the shell) interacted with the environment in a manner opposite to that of the caudate. That is, the net effect of heroin was smaller when the treatment was administered in association with environmental 'novelty' than when it was administered at home. This is surprising because exposure to the 'novel' context per se produced a robust increase in Fos protein levels in the nucleus accumbens but not in the caudate. Similar results were previously obtained with amphetamine and cocaine (Badiani et al, 1998; Uslaner et al, 2001a). Taken together these findings clearly indicate that the interaction among drug and environment cannot be simply reduced to the sum of the changes induced independently by drugs and environmental stimuli.

In summary, the interaction between environment, heroin, and drug history in regulating Fos levels in the 
striatal complex presented important regional differences, which is not surprising given the complexity of the structural and functional organization of the striatal complex (for example, see Gerfen, 1992; Joel and Weiner, 2000; Riedel et al, 2002; Levesque et al, 2003). Animals that were injected with saline in a test environment different from the home cage and to which they had been exposed previously (ie, a 'novel' environment) exhibited higher levels of Fos in the nucleus accumbens, but not in the caudate, relative to animals injected with saline at home (see Table 1). This is consistent with the fact that the nucleus accumbens (particularly the shell) is the region of the striatal complex most responsive to physical and psychological stressors (Fadda et al, 1978; Kalivas and Duffy, 1995; Noguchi et al, 2001). In contrast, it is not clear why the net effect of heroin on Fos expression in the caudate was greater in the animals exposed to 'novelty' than in the rats tested in the home cage, whereas the opposite pattern was observed in the nucleus accumbens (expecially in the shell). Similar results were previously obtained in studies with amphetamine and cocaine (Badiani et al, 1998; Uslaner et al, 2001a). It is possible that these regional differences were due to the preferential innervation of the caudate by glutamatergic projections from somatosensory cortex (see below). Finally, in the dorsal caudate context-dependent differences in heroin-induced Fos expression were larger in heroinpretreated than in saline-pretreated rats whereas the opposite was observed in the ventral caudate and in the nucleus accumbens, suggesting a role of this portion of the caudate in the expression of heroin sensitization. Interestingly, Mikkola et al (2000) reported sensitization of morphine-induced dopamine overflow in the dorsal caudate, but not in the nucleus accumbens, of rats repeatedly treated with doses of morphine comparable to those used in the present study $(4-12 \mathrm{mg} / \mathrm{kg}$, i.p., over a 4-day period). Using much higher doses of morphine (for a total of $140 \mathrm{mg} / \mathrm{kg}$, s.c., over a 3-day period), however, Cadoni et al (2000) found sensitized dopamine overflow in the caudate and in the core, but not in the shell, of nucleus accumbens.

\section{Environmental Modulation of Heroin-Induced Fos Expression in the Cortex}

Mere exposure to environmental novelty powerfully induces Fos expression in the primary somatosensory cortex, as observed previously for Fos mRNA expression (Papa et al, 1993; Badiani et al, 1998; Uslaner et al, 2001b; Ostrander et al, 2003).

Fos expression in the barrel field cortex was not altered by heroin per se whereas it was enhanced when heroin was administered in association with environmental 'novelty'. This overall effect masked opposite heroin-induced changes in layer IV (where heroin powerfully enhanced Fos expression relatively to the control group) vs layers II/III (where heroin reduced Fos expression). It was previously found that amphetamine and cocaine have relatively little effect on Fos mRNA expression in the barrel field cortex of rats exposed to novelty (Badiani et al, 1998; Uslaner et al, 2001a; Ostrander et al, 2003) but in these earlier studies no attempt was made to quantify Fos expression in the different cortical layers.
Pretreatment with heroin in novelty rats dramatically altered the effect of heroin on Fos expression in layer IV (where it went from potentiation to suppression) as well as in layers II/III and V/VI (where the suppression became stronger). Indeed, in these animals heroin powerfully suppressed Fos expression in all layers of the barrel field cortex. This finding stands in apparent contrast with the results of a study by Curran et al (1996), who reported that morphine-induced Fos mRNA expression in the somatosensory cortex was increased by repeated pretreatments with the same drug. Notice, however, that in the study by Curran et al (1996) the animals received morphine under conditions similar to those of our home animals, which in fact exhibited a modest, nonsignificant increase in Fos expression after repeated exposure to heroin. Alternatively, it is necessary to hypothesize that net effects of morphine and heroin on Fos expression in the neocortex are not completely overlapping.

Not surprisingly, there was a strong correlation between heroin-induced Fos expression in the barrel field cortex and in the caudate of the animals tested under 'novelty' conditions. Indeed, there are direct connections between adjacent cortical and striatal areas (for a review, see Heimer et $a l, 1995)$ and the activation of corticostriatal projections has been shown to induce c-fos mRNA expression in the striatum (Wan et al, 1992; Fu and Beckstead, 1992; Berretta et al, 1997; Sgambato et al, 1997). The corticostriatal projection may relay the sensory information about the environment from the thalamus to the caudate. Thus, it is tempting to attribute the modulatory action of environment on heroin-induced Fos expression in the caudate to the interaction of mesostriatal dopaminergic and corticostriatal glutamatergic inputs (Liu et al, 1994; Bontempi and Sharp, 1997; Garcia et al, 2003). For example, it has been shown that the administration of NMDA receptor antagonists or the transection of corticostriatal fibers reduce the effects of environment on amphetamine-induced Fos mRNA expression in the caudate (Ferguson et al, 2003; Ferguson and Robinson, 2004). Interestingly, no correlation in Fos levels was found between any cortical layer and caudate in the home group suggesting that under these environmental conditions corticostriatal projections were relatively quiescent.

\section{Heroin-Induced Fos Expression and Psychomotor Activity}

The ability of heroin to induce Fos protein expression in both the neocortex and the striatal complex is interesting because this transcription factor can serve as an indicator of neuronal activity (Hughes and Dragunow, 1995; Harlan and Garcia, 1998) and is thought to be involved in drug-induced neurobehavioral plasticity (Hyman and Malenka, 2001; Nestler, 2001; Ujike et al, 2002).

There was no simple relationship between heroin-induced psychomotor activity and the activity of any single brain region, at least as indicated by Fos protein levels. This is not surprising because it is reasonable to assume that the complex interaction between environmental context, drug history, and heroin depends on the interplay of several brain regions. Indeed, multiple regression analysis indicated that Fos protein levels in the postero-dorsal caudate, in the 
shell of the nucleus accumbens, and in the barrel field cortex can predict most of the variance in heroin-induced activity scores, which is quite plausible given the wellknown involvement of these regions in modulating druginduced psychomotor activity, drug-induced sensitization, and sensory information. Of course, it is also possible that the activity of these brain regions merely reflect the activity of other structures not investigated in the present study and that may be responsible at a more fundamental level for the interaction between heroin and environment.

\section{CONCLUSIONS}

The present report demonstrates that environment and drug history powerfully interact in shaping the neurobehavioral response to heroin. The importance of such an interaction is also shown by the results of studies with amphetamine (Ostrander et al, 2003) and cocaine (Li et al, 2003; Hope et al, 2006). Thus, an understanding of the mechanisms responsible for the neurobehavioral adaptations produced by addictive drugs will also require taking into due account the environment in which drugs are experienced. Preliminary data from our group indicating that environmental context has a powerful influence on the acquisition of cocaine and heroin self-administration in the rat further emphasize the importance of this issue.

\section{ACKNOWLEDGEMENTS}

This work was supported by grants from the University of Rome La Sapienza (Fondi di Ateneo e Fondi di Facoltà) and from the Italian Ministry for University and Research (PRIN).

\section{REFERENCES}

Antonilli L, Petecchia E, Caprioli D, Badiani A, Nencini P (2005). Effect of repeated administrations of heroin, naltrexone, methadone, and alcohol on morphine glucuronidation in the rat. Psychopharmacology (Berlin) 182: 58-64.

Antonilli L, Semeraro F, Suriano C, Signore L, Nencini P (2003a). High levels of morphine-6-glucuronide in street heroin addicts. Psychopharmacology (Berlin) 170: 200-204.

Antonilli L, Suriano C, Paolone G, Badiani A, Nencini P (2003b). Repeated exposures to heroin and/or cadmium alter the rate of formation of morphine glucuronides in the rat. J Pharmacol Exp Ther 307: 651-660.

Badiani A, Anagnostaras SG, Robinson TE (1995a). The development of sensitization to the psychomotor stimulant effects of amphetamine is enhanced in a novel environment. Psychopharmacology (Berlin) 117: 443-452.

Badiani A, Browman KE, Robinson TE (1995b). Influence of novel versus home environments on sensitization to the psychomotor stimulant effects of cocaine and amphetamine. Brain Res 674: 291-298.

Badiani A, Camp DM, Robinson TE (1997). Enduring enhancement of amphetamine sensitization by drug-associated environmental stimuli. J Pharmacol Exp Ther 282: 787-794.

Badiani A, Oates MM, Day HEW, Watson SJ, Akil H, Robinson TE (1998). Amphetamine-induced behavior, dopamine release and c-fos mRNA expression: modulation by environmental novelty. J Neurosci 18: 10579-10593.

Badiani A, Oates MM, Day HEW, Watson SJ, Akil H, Robinson TE (1999). Environmental modulation of amphetamine-induced c-fos expression in D1 versus D2 striatal neurons. Behav Brain Res 103: 203-209.

Badiani A, Oates MM, Robinson TE (2000). Modulation of morphine sensitization in the rat by contextual stimuli. Psychopharmacology (Berlin) 151: 273-282.

Badiani A, Robinson TE (2004). Drug-induced neurobehavioral plasticity: the role of environmental context. Behav Pharmacol 15: 327-339.

Berretta S, Parthasarathy HB, Graybiel AM (1997). Local release of GABAergic inhibition in the motor cortex induces immediateearly gene expression in indirect pathway neurons of the striatum. J Neurosci 17: 4752-4763.

Bontempi B, Sharp FR (1997). Systemic morphine-induced Fos protein in the rat striatum and nucleus accumbens is regulated by $\mathrm{mu}$ opioid receptors in the substantia nigra and ventral tegmental area. J Neurosci 17: 8596-8612.

Browman KE, Badiani A, Robinson TE (1998a). Modulatory effect of environmental stimuli on the susceptibility to amphetamine sensitization: a dose-effect study in rats. J Pharmacol Exp Ther 287: 1007-1014.

Browman KE, Badiani A, Robinson TE (1998b). The influence of environment on the induction of sensitization to the psychomotor activating effects of intravenous cocaine in rats is dosedependent. Psychopharmacology (Berlin) 137: 90-98.

Cadoni C, Solinas M, Di Chiara G (2000). Psychostimulant sensitization: differential changes in accumbal shell and core dopamine. Eur J Pharmacol 388: 69-76.

Conversi D, Orsini C, Cabib S (2004). Distinct patterns of Fos expression induced by systemic amphetamine in the striatal complex of C57BL/6JICo and DBA/2JICo inbred strains of mice. Brain Res 1025: 59-66.

Crombag HS, Badiani A, Robinson TE (1996). Signalled versus unsignalled intravenous amphetamine: large differences in the acute psychomotor response and sensitization. Brain Res 722: 227-231.

Curran EJ, Akil H, Watson SJ (1996). Psychomotor stimulantand opiate-induced c-fos mRNA expression patterns in the rat forebrain: comparisons between acute drug treatment and a drug challenge in sensitized animals. Neurochem Res 21: 1425-1435.

D'Este L, Scontrini A, Casini A, Pontieri FE, Renda TG (2002). Heroin sensitization as mapped by c-Fos immunoreactivity in the rat striatum. Brain Res 933: 144-149.

Day HEW, Badiani A, Uslaner JM, Oates MM, Vittoz NM, Robinson TE et al (2001). Environmental novelty differentially affects c-fos mRNA expression induced by amphetamine or cocaine in subregions of the bed nucleus of the stria terminalis and amygdala. J Neurosci 21: 732-740.

De Vries TJ, Schoffelmeer AN, Binnekade R, Mulder AH, Vanderschuren LJ (1998). Drug-induced reinstatement of heroin- and cocaine-seeking behaviour following long-term extinction is associated with expression of behavioural sensitization. Eur J Neurosci 10: 3565-3571.

Devine DP, Leone P, Pocock D, Wise RA (1993). Differential involvement of ventral tegmental mu, delta and kappa opioid receptors in modulation of basal mesolimbic dopamine release: in vivo microdialysis studies. J Pharmacol Exp Ther 266: 1236-1246.

Everitt BJ, Wolf ME (2002). Psychomotor stimulant addiction: a neural systems perspective. J Neurosci 22: 3312-3320.

Fadda F, Argiolas A, Melis MR, Tissari AH, Onali PL, Gessa GL (1978). Stress-induced increase in 3, 4-dihydroxyphenylacetic acid (DOPAC) levels in the cerebral cortex and in n. accumbens: reversal by diazepam. Life Sci 23: 2219-2224.

Ferguson SM, Norton CS, Watson SJ, Akil H, Robinson TE (2003). Amphetamine-evoked c-fos mRNA expression in the caudateputamen: the effects of DA and NMDA receptor antagonists vary as a function of neuronal phenotype and environmental context. J Neurochem 86: 33-44. 
Ferguson SM, Robinson TE (2004). Amphetamine-evoked gene expression in striatopallidal neurons: regulation by corticostriatal afferents and the ERK/MAPK signaling cascade. J Neurochem 91: 337-348.

Ferguson SM, Thomas MJ, Robinson TE (2004). Morphineinduced c-fos mRNA expression in striatofugal circuits: modulation by dose, environmental context, and drug history. Neuropsychopharmacology 29: 1664-1674.

Fraioli S, Crombag HS, Badiani A, Robinson TE (1999). Susceptibility to amphetamine-induced locomotor sensitization is modulated by environmental stimuli. Neuropsychopharmacology 20: $533-541$.

Fu L, Beckstead RM (1992). Cortical stimulation induces fos expression in striatal neurons. Neuroscience 46: 329-334.

Garcia MM, Anderson AT, Edwards R, Harlan RE (2003). Morphine induction of $\mathrm{c}$-fos expression in the rat forebrain through glutamatergic mechanisms: role of non-N-methyl-Daspartate receptors. Neuroscience 119: 787-794.

Gerfen CR (1992). The neostriatal mosaic: multiple levels of compartmental organization. J Neural Transm Suppl 36: 43-59.

Haemmig RB, Tschacher W (2001). Effects of high-dose heroin versus morphine in intravenous drug users: a randomised double-blind crossover study. J Psychoactive Drugs 33: 105-110.

Harlan RE, Garcia MM (1998). Drugs of abuse and immediateearly genes in the forebrain. Mol Neurobiol 16: 221-267.

Heimer L, Zahm DS, Alheid GF (1995). Basal ganglia. In: Paxinos G (ed). The Rat Nervous System, 2nd edn. Academic Press: San Diego. pp 689-704.

Hope BT, Simmons DE, Mitchell TB, Kreuter JD, Mattson BJ (2006). Cocaine-induced locomotor activity and Fos expression in nucleus accumbens are sensitized for 6 months after repeated cocaine administration outside the home cage. Eur J Neurosci 24: 867-875.

Hughes P, Dragunow M (1995). Induction of immediate-early genes and the control of neurotransmitter-regulated gene expression within the nervous system. Pharmacol Rev 47: 133-178.

Hutcheson DM, Parkinson JA, Robbins TW, Everitt BJ (2001). The effects of nucleus accumbens core and shell lesions on intravenous heroin self-administration and the acquisition of drug-seeking behaviour under a second-order schedule of heroin reinforcement. Psychopharmacology (Berlin) 153: 464-472.

Hyman SE, Malenka RC (2001). Addiction and the brain: the neurobiology of compulsion and its persistence. Nat Rev Neurosci 2: 695-703.

Jacobs EH, de Vries TJ, Smit AB, Schoffelmeer AN (2004). Gene transcripts selectively down-regulated in the shell of the nucleus accumbens long after heroin self-administration are up-regulated in the core independent of response contingency. FASEB $J$ 18: $200-202$.

Joel D, Weiner I (2000). The connections of the dopaminergic system with the striatum in rats and primates: an analysis with respect to the functional and compartmental organization of the striatum. Neuroscience 96: 451-474.

Johnson SW, North RA (1992). Opioids excite dopamine neurons by hyperpolarization of local interneurons. J Neurosci 12: 483-488.

Kalivas PW, Duffy P (1995). Selective activation of dopamine transmission in the shell of the nucleus accumbens by stress. Brain Res 675: 325-328.

Kendall JM, Reeves BC, Latter VS, Nasal Diamorphine Trial Group (2001). Multicentre randomised controlled trial of nasal diamorphine for analgesia in children and teenagers with clinical fractures. BMJ 322: 261-265.

Levesque M, Bedard A, Cossette M, Parent A (2003). Novel aspects of the chemical anatomy of the striatum and its efferents projections. J Chem Neuroanat 26: 271-281.
Li Y, Kolb B, Robinson TE (2003). The location of persistent amphetamine-induced changes in the density of dendritic spines on medium spiny neurons in the nucleus accumbens and caudate-putamen. Neuropsychopharmacology 28: 1082-1085.

Liu J, Nickolenko J, Sharp FR (1994). Morphine induces c-fos and junB in striatum and nucleus accumbens via D1 and N-methyl-D-aspartate receptors. Proc Natl Acad Sci USA 91: 8537-8541.

Marinelli M, Le Moal M, Piazza PV (1998). Sensitization to the motor effects of contingent infusions of heroin but not of kappa agonist RU 51599. Psychopharmacology (Berlin) 139: 281-285.

Matthews RT, German DC (1984). Electrophysiological evidence for excitation of rat ventral tegmental area dopamine neurons by morphine. Neuroscience 11: 617-625.

Mikkola JA, Honkanen A, Piepponen TP, Kiianmaa K, Ahtee L (2000). Effects of repeated morphine on cerebral dopamine release and metabolism in AA and ANA rats. Pharmacol Biochem Behav 67: 783-791.

Moleman P, Bruinvels J (1979). Morphine-induced striatal dopamine efflux depends on the activity of nigrostriatal dopamine neurones. Nature 281: 686-687.

Nestler EJ (2001). Molecular basis of long-term plasticity underlying addiction. Nat Rev Neurosci 2: 119-128.

Noguchi T, Yoshida Y, Chiba S (2001). Effects of psychological stress on monoamine systems in subregions of the frontal cortex and nucleus accumbens of the rat. Brain Res 916: 91-100.

Ostrander MM, Badiani A, Day HEW, Norton CS, Watson SJ, Akil $\mathrm{H}$ et al (2003). Environmental context and drug history modulate amphetamine-induced c-fos mRNA expression in the basal ganglia, central extended amygdala, and associated limbic forebrain. Neuroscience 120: 551-571.

Paolone G, Burdino R, Badiani A (2003). Dissociation in the modulatory effects of environmental novelty on the locomotor, analgesic, and eating response to acute and repeated morphine in the rat. Psychopharmacology (Berlin) 166: 146-155.

Papa M, Pellicano MP, Welzl H, Sadile AG (1993). Distributed changes in c-Fos and c-Jun immunoreactivity in the rat brain associated with arousal and habituation to novelty. Brain Res Bull 32: 509-515.

Pasternak GW (2001). Incomplete cross tolerance and multiple mu opioid peptide receptors. Trends Pharmacol Sci 22: 67-70.

Paxinos G, Watson C (1997). The Rat Brain in Stereotaxic Coordinates. Academic Press: San Diego.

Pontieri FE, Calo L, Di Grezia R, Orzi F, Passarelli F (1997). Functional correlates of heroin sensitization in the rat brain. Eur J Pharmacol 335: 133-137.

Rady JJ, Roerig SC, Fujimoto JM (1991). Heroin acts on different opioid receptors than morphine in Swiss Webster and ICR mice to produce antinociception. J Pharmacol Exp Ther 256: 448-457.

Riedel A, Hartig W, Seeger G, Gartner U, Brauer K, Arendt T (2002). Principles of rat subcortical forebrain organization: a study using histological techniques and multiple fluorescence labeling. J Chem Neuroanat 23: 75-104.

Robinson TE, Becker JB (1986). Enduring changes in brain and behavior produced by chronic amphetamine administration: a review and evaluation of animal models of amphetamine psychosis. Brain Res 396: 157-198.

Robinson TE, Berridge KC (2000). The psychology and neurobiology of addiction: an incentive-sensitization view. Addiction 95(Suppl 2): S91-S117.

Schuller AG, King MA, Zhang J, Bolan E, Pan YX, Morgan DJ et al (1999). Retention of heroin and morphine-6 beta-glucuronide analgesia in a new line of mice lacking exon 1 of MOR-1. Nat Neurosci 2: 151-156.

Sgambato V, Abo V, Rogard M, Besson MJ, Deniau JM (1997). Effect of electrical stimulation of the cerebral cortex on the expression of the Fos protein in the basal ganglia. Neuroscience 81: $93-112$. 
Shalev U, Grimm JW, Shaham Y (2002). Neurobiology of relapse to heroin and cocaine seeking: a review. Pharmacol Rev 54: 1-42.

Spyraki C, Fibiger HC, Phillips AG (1983). Attenuation of heroin reward in rats by disruption of the mesolimbic dopamine system. Psychopharmacology (Berlin) 79: 278-283.

Stewart J, Badiani A (1993). Tolerance and sensitization to the behavioral effects of drugs. Behav Pharmacol 4: 289-312.

Stewart J, Vezina P (1988). A comparison of the effects of intra-accumbens injections of amphetamine and morphine on reinstatement of heroin intravenous self-administration behavior. Brain Res 457: 287-294.

Tschacher W, Haemmig R, Jacobshagen N (2003). Time series modeling of heroin and morphine drug action. Psychopharmacology (Berlin) 165: 188-193.

Ujike H, Takaki M, Kodama M, Kuroda S (2002). Gene expression related to synaptogenesis, neuritogenesis, and MAP kinase in behavioral sensitization to psychostimulants. Ann NY Acad Sci 965: 55-67.

Uslaner J, Badiani A, Day HEW, Watson SJ, Akil H, Robinson TE (2001a). Environmental Context modulates the ability of cocaine and amphetamine to induce c-fos mRNA expression in the neocortex, caudate nucleus, and nucleus accumbens. Brain Res 920: 106-116.

Uslaner J, Badiani A, Norton CS, Day HEW, Watson SJ, Akil H et al (2001b). Amphetamine and cocaine induce different patterns of c-fos mRNA expression in the striatum and subthalamic nucleus depending on environmental context. Eur J Neurosci 13: 1977-1983.

Vaccarino FJ, Bloom FE, Koob GF (1985). Blockade of nucleus accumbens opiate receptors attenuates intravenous heroin reward in the rat. Psychopharmacology (Berlin) 86: 37-42.

Vaccarino FJ, Corrigall WA (1987). Effects of opiate antagonist treatment into either the periaqueductal grey or nucleus accumbens on heroin-induced locomotor activation. Brain Res Bull 19: 545-549.

Vanderschuren LJ, Kalivas PW (2000). Alterations in dopaminergic and glutamatergic transmission in the induction and expression of behavioral sensitization: a critical review of preclinical studies. Psychopharmacology (Berlin) 151: 99-120.

Wan XS, Liang F, Moret V, Wiesendanger M, Rouiller EM (1992). Mapping of the motor pathways in rats: c-fos induction by intracortical microstimulation of the motor cortex correlated with efferent connectivity of the site of cortical stimulation. Neuroscience 49: 749-761.

White FJ, Kalivas PW (1998). Neuroadaptations involved in amphetamine and cocaine addiction. Drug Alcohol Depend 51: 141-153.

Wise RA (1989). Opiate reward: sites and substrates. Neurosci Biobehav Rev 13: 129-133. 